\title{
The ludic and the child with cancer: a bibliographic review
}

\begin{abstract}
Childhood cancer is a group of diseases that have in common the uncontrolled proliferation of anormal cells that can occur anywhere in the body. The aim of this study was to know the scientific production on the ludic and the child with cancer. This is a systematic bibliographical review carried out in the databases PUBMED, LILACS and SCIELO. The results of this study were articles mainly point out the difficulties arising from the diagnosis of cancer in the child's life, such as physical and routine changes. The ludic presents as beneficial in the hospital treatment, through the therapeutic toy, the toy library or recreation activities. However the ludic in the home context didn't are shoewd in this results.
\end{abstract}

Volume 5 Issue 2 - 2018

\author{
Juliana A Rockembach, Muniz RM \\ Deapartment of Nursing, Universidade Federal de Pelotas, Brazil
}

Correspondence: Juliana A Rockembach, Deapartment of Nursing, Universidade Federal de Pelotas, Brazil, Email ju.rockembach@hotmail.com

Received: February 20, 20I8 | Published: March I4, 2018

\section{Introduction}

Childhood cancer is a group of diseases that have in common the uncontrolled proliferation of abnormal cells that can occur anywhere in the body. It represents an important cause of morbidity and mortality in Brazil, with a growing incidence of approximately $1 \%$ per year, being the second cause of death in the population under 14 years, inferior only to accidents and other external causes. Its most common forms are: leukemias, tumors of the central nervous system, lymphomas and renal tumors. Currently, about $70 \%$ of children can be cured, if diagnosed early and treated in specialized centers. ${ }^{1}$

Upon receiving the diagnosis of cancer, the child and his family experience a new period in their lives, in which they have to adapt to the new reality, changing the dynamics and family routine. The child becomes the focus of the whole family, having needs arising from the disease and the treatment in which it is being submitted, examinations, prolonged hospitalizations, physical and psychological impacts. All this change in the child life exposes that to pain, suffering as well as cause an abrupt change in them social and family life. ${ }^{2-4}$

Although the cancer does not interrupt the child development process, some restrictions are imposed on this child on diagnosis and treatment. Thus, child care should provide a complete state of physical, social, and mental well-being. It is of extreme relevance to take into consideration all basic children's needs, among them, the act of playing and all the playfulness that involves being a child. Thus, this study had as guiding question "What scientific production on the playful and the child with cancer?"

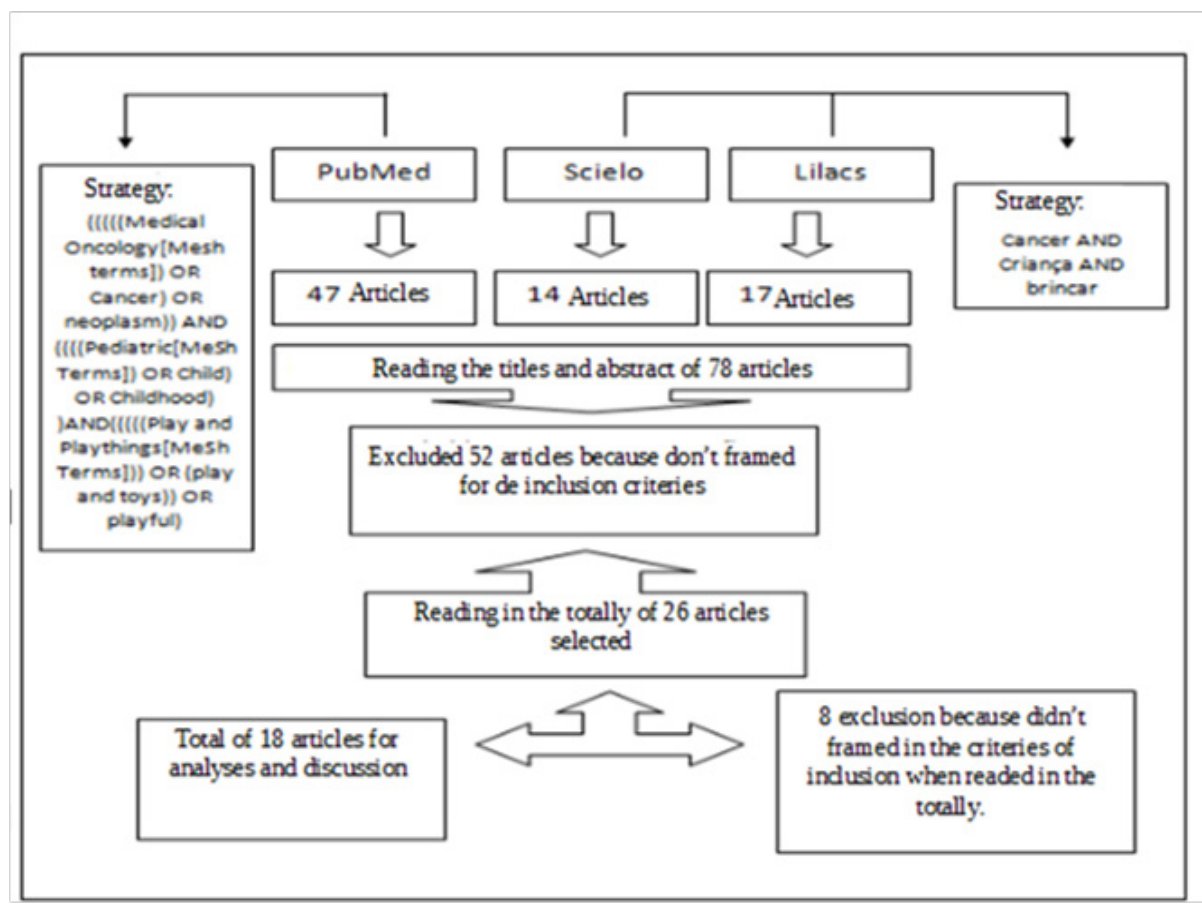

Figure I Health Sciences Descriptors database. 


\section{Objective}

To know the scientific production on the ludic and the child with cancer.

\section{Methodology}

This is a systematic bibliographical review, carried out in the databases PUBMED, LILACS and SCIELO. The inclusion criterion was articles that deal with play and children with neoplasia, published in the last 10 years, in the Portuguese, English and Spanish languages. The exact descriptors used were taken from the Health Sciences Descriptors database (DECS), including: Medical Oncology, Pediatric, and Play and Playthings. The following terms were used as keywords: Cancer, neoplasms, child, childhood, play and toys, and playful. The booleans used were and and or.

\section{Results}

The articles mainly point out the difficulties arising from the diagnosis of cancer in the child's life, such as physical and routine changes. The ludic presents as beneficial in the hospital treatment, through the therapeutic toy, the toy library or recreation activities. The play was also reported as a way to explain to the child the procedures and the relevance of the same to his recovery. However, the use of leisure activities by the health team was pointed out as being of difficult applicability due to the work routine and the lack of time due to the intense demand in the hospital environment. ${ }^{5}$ The ludic in the home context for children in outpatient treatment was addressed in only four articles, all of the same authors, demonstrating that despite the great advances in pediatric oncology outpatient treatment, studies that involve the theme still need to be further explored in the academic and scientific community.

\section{Conclusion}

One can see that playfulness is seen as inherent in caring for the child with cancer. However, the researches are focused on the impact of therapeutic toy and play in the hospital context. With the advances of outpatient treatment, the child spends more time in his home context, being considered of great relevance more studies that aim the theme in this scenario.

\section{Acknowledgements}

None.

\section{Conflict of interest}

The author declares that there is no conflict of interest.

\section{References}

1. Ministry of Health (BR). National Cancer Institute. Estimate 2014: incidence of cancer in Brazil. Rio de Janeiro, Brazil (RJ), 2014.

2. Silva LF, Cabral IE. The rescue of the pleasure of playing the child with cancer in hospital space. Rev bras enferm. 2015;68(3):391-397.

3. Silva LF, Cabral IE, Christoffel MM. Playing in the schoolboy's life with cancer in outpatient treatment: (Im) possibilities for development. Rev Bras Crescimento Human development. 2008;18(3):275-287.

4. Silva LF, Cabral IE, Christoffel MM. The (im) possibilities of playing for the schoolchild with cancer in outpatient treatment. Acta Paul Enferm. 2010:23(3):334-40.

5. Hildebrand A, Clawson M, Alderfer M, et al. Coping with pediatric cancer: strategies employed by children and their parents to manage cancerrelated stressors during treatment. $J$ Pediatr Oncol Nurs. $2011 ; 28(6): 344-354$ 